\title{
HIGHER EDUCATION FOR BUSINESS PURSUITS AND MANUFACTURING
}

\author{
JoHn H. Converse
}

Baldwin Locomotive Works, Philadelphia.

This subject, as formulated, assumes the need and value of training for business and industrial pursuits. No argument is necessary to establish this fact. It is just as true that suitable training is required for a business career as that suitable training is required for the professions, so called. It is equally true that, until a comparatively recent period, no direct provision has been made in our educational systems for a preparation for business.

Two theories of education are held: one that the proper method is the development of the faculties of the student without reference to ulterior pursuits, and the other that the course of study should be informing and directed to the proper mental equipment. We cannot deny the value of general culture. It is true that the properly trained mind can adapt itself to requirements of every description; but this view assumes what may not be admitted - that both culture and training cannot be effected in a properly selected curriculum. Who shall say that the study of the natural sciences is not as valuable for purposes of culture as the study of metaphysics, or that the study of mathematics in their application to mechanical principles is not more effective for culture than their study in the abstract? Can it be maintained that the study of modern history and commercial geography is less effective in promoting the training of the faculties than the study of ancient history and archæology? It is the discipline of difficulty which counts; and if the subjects on which the faculties are exercised are such as may prove valuable and informing for future use, there is no ground for their condemnation. If, then, these two theories of education can be harmonized, the solution of the problem is at hand.

Our subject requires the consideration of the relative position in any curriculum, of special training and, incidentally, of the time

[115] 
which should be allotted to such studies. In order to properly consider this point it is necessary at the outset to define what we mean by "business." The term has a much broader significance now than it had 250 or 200 years ago, when the first American colleges were founded. Then it meant almost exclusively the retail sale of commodities. The transactions involved were of the simplest character. Barter, the exchange of one article for another, constituted the main function. Finance as a science was not involved. There was confessedly little room for eminent intellectual qualifications. There were no manufactures worthy of the name in this country prior to the Revolution. The English policy was to maintain its manufactures at home and to use its colonies as consumers, receiving in exchange the products of the soil and the ocean.

There were no inland transportation problems of importance. The pack horse or the Conestoga wagon was the sum of this interest. There was little or no commercial finance. Banks were few and inadequate for private enterprise. Legislatures were slow to grant charters. Banks were regarded rather as monopolies than as aids to business efforts. The Legislature of Pennsylvania demanded a payment of $\$ 135,000$ in consideration of the grant of a charter in 1804 to the Philadelphia Bank.

Insurance as a business was unknown, except as to marine risks. Life insurance, based as it is on scientific data, had not been evolved, and fire insurance was only developed toward the close of the eighteenth century. Such were the conditions when the original American colleges were founded. Small wonder that they did not recognize business pursuits, limited and simple as they then were, as fitting careers for their beneficiaries. On the contrary, their avowed object was, at the first, chiefly the training of men for the Christian ministry. The purpose of the founding of Harvard was stated to be "in order that the Church might have able pastors and that learning might not be buried in the graves of the fathers." Yale was founded in I7Or by a number of Connecticut ministers. The object set forth in the charter was " that youth may be instructed in the arts and sciences, who, through the blessing of Almighty God may be fitted for further employment, both in Church and civil State."

In contrast with the conditions originally prevailing, we may 
attempt to indicate what is included in the term "business" to-day. Its significance has been greatly enlarged. It covers a vast range of processes and industries. It affords opportunities to utilize nearly every branch of learning included in a university curriculum. A single pursuit may call in play qualifications most diverse. Perhaps the leading pursuits which are covered by the general title "business" are:

Mercantile transactions, wholesale and retail.

The importation and exportation of commodities.

Transportation, by railroad, by vessel, and otherwise.

Insurance - fire, marine, and life.

Mines.

Manufactures.

Agriculture.

Finance.

What, then, we may inquire, are the features of some of these vocations, which may afford fitting fields for the abilities of college graduates?

First, as to mercantile transactions. Their scope to-day is much broader than the mere sale of commodities. Stocks of goods are purchased in the markets of the world. Foreign countries must contribute. Familiarity with the products and the processes of other lands is necessary. A knowledge of other languages is essential. Physical geography is an element. Details of manufacturing processes are involved. The buyer, possessing these qualifications, is even more important than the seller. Then over all, or co-ordinating with all, is the executive management, involving ability in organization and conduct, in finance, in importing, in shipping and in transportation. A business like Mr. Wanamaker's, for example, has 5,068 salespeople and 6,243 other than salespeople, such as buyers, managers, clerks, and accountants, who are seldom visible to the ordinary customer.

Closely related to trade is transportation. This, with its movement of merchandise and passengers, has come to be one of the greatest interests of modern times. Independent of water carriage, the matter of land transportation by railways has become in this century one of the largest industries. The United States has now over 200,000 miles of steam railways and over 30,000 miles of electric lines. It is a fair estimate that these give employment to near- 
ly $1,500,000$ of operatives, and they, in turn, represent $7,500,000$ men, women and children, or nearly one-tenth of our population.

In the conduct of this vast interest a large variety of ability is demanded. Mechanical knowledge, engineering skill, scientific attainments, familiarity with agricultural and mineralogical conditions, executive force and financial ability of a high order - all are required in the various functions of a successful railroad man. In fact, in the head of any great railroad system a combination of many, if not all of these requirements, is invaluable. Hence, it will be found in many cases that one who has the advantages of such a liberal education as an engineering or a professional course supplies is naturally most competent for the leadership of these vast enterprises. Mr. Cassatt is a civil engineer by profession; Mr. Baer a lawyer.

Another branch of business which has grown to large proportions in modern times is insurance. This is of comparatively recent origin. The method and plans of university education were formulated more than one hundred years before the beginning of this interest. The first office for fire insurance in the United States was opened in Philadelphia in I752. To-day there are thousands of companies and agencies.

Another branch of the business, viz., life insurance, is of more recent growth. The Pennsylvania Company for Insurance on Lives and Granting Annuities was incorporated in I812, and was followed by other corporations having similar objects; but the great business of life insurance, as we know it, may be said to be only a little over fifty years old. In I843, the Mutual Life Insurance Company, of New York, and the New England Life Insurance Company began business. To-day the number of companies has greatly increased, and the capital involved is immense. At the close of I9OI the assets of the various United States companies had involved the enormous aggregate of $\$ 1,879,624,564$, and there were $7,500,000,000$ risks out. The assets of a single leading United States company, as last reported, approximated $\$ 350,000,000$. The business of life insurance, therefore, involves the custody and maintenance of this enormous capital. Investments must be found for this vast accumulation of money. Business ability of a high order and of varied character is required to pass upon the merits of the enterprises of all descriptions in which funds must be put to 
insure their safe preservation and liberal yield of income. Most of us, perhaps, have derived our ideas of life insurance from the irrepressible solicitor, who makes life a burden to us until we have taken a policy. But this is only an incident and a small part of what is involved in this vast interest in the light of recent developments.

Included in the realm of business is the enormous interest of manufactures. To this we may give supreme position. It is the creation, out of the raw material of nature, of articles for the comfort, convenience and happiness of mankind. If the old saying be true that "he is a benefactor of the race who makes two blades of grass grow where one grew before," much more is it true that he merits the highest place among his fellows who transforms the crude substances of the earth into the finished product which makes for human welfare and which differentiates civilized man from the savage. In the processes involved there is room for ability and knowledge the most varied and extensive. The command of man over nature elevates him to a god-like position.

America has now taken a leading place among the manufacturing nations of the earth. In the variety and quality of products we are unsurpassed. Our textiles find a market in every land. Our agricultural machinery harvests the crops on the plains of Australia and the steppes of Russia. Our typewriters and sewing machines are manipulated by operators of every color and language. Our locomotives cross the deserts of Africa - convey the tourist to the Holy City of Jerusalem, astonish the teeming millions of the Flowery Kingdom, and have transported armies across the Siberian wilderness to the late conflict in the Far East. The value of the exports of manufactured articles from us has risen to over $\$ 450$,ooo,ooo annually.

To meet these conditions of modern business life the most complete training is required. There are few, if any, subjects in the modern college curricula which will not come in play, as no man can tell what his career will be or what conditions he may have to meet. The fullest command of all the subjects may be required. The man of affairs to-day may find use, not only for technical knowledge, but for whatever is given by the broadest culture. Some knowledge of both the ancient and modern languages may be required. 
Linguistic knowledge of every description, as producing effective ability in composition and style, is a valuable acquisition.

In this connection another accomplishment may be mentioned, which, I fear, is too often neglected in the modern college curriculum. I refer to public speaking. The ability to speak well, freely, logically, and with some degree of grace and eloquence, counts for much, even in mercantile pursuits. It distinguishes a man and secures admiration and respect. I realize the fact that lawyers are more frequently found in public life than business men, and it may be largely attributed to their training as public speakers. This qualification brings them before the public, and there is nothing which so completely compels recognition and esteem. There is no reason why a business man with the gift of oratory should not be, if otherwise fully educated, as competent for public service or political office as the lawyer. In fact, in handling most questions, his qualifications would be superior. In legislation it is often the solution of questions of a business character which counts. A business man, therefore, whose training has qualified him to grapple with such questions, and who can express himself logically and forcibly in maintenance of his views, should occupy a strong position in public life. I think it is a fact that the best lawyers are those who also are the best business men. Add to a knowledge of the methods and problems of business an equally thorough knowledge of the law, as applicable thereto, and you have the highest type of excellence in our present state of society. Is not this a tacit recognition of the value of business training and business methods?

To the question, "What is lacking in the equipment which the ordinary college training yields?" the answer must be given that very little except general culture is produced. Training for any specific pursuit is not included in the usual curriculum. The college does not consider it within its province to teach bookkeeping, stenography, typewriting or even penmanship and spelling. These are usually left to the business college. The graduate is without any specific qualifications for the beginning of a business career. In almost every business one of three things is required for a beginner. First, bookkeeping, if for the accounting department. Second, stenography and typewriting or penmanship, if for the general or correspondence department; and third, special talent for the sales department. This is the trinity of business requirements 
of the beginner. The college course does not give any one. The value of these is in gaining a foothold in business, and not in filling any one of them for life. The young man or young woman, beginning as a bookkeeper or stenographer, achieves a connection with business and gains knowledge of the business. Other faculties will come into play, and promotion to more important service will follow. In this way many, conspicuous for executive ability, have begun their careers. It would be well if every college student who contemplates a business career had these qualifications; for, if they are not given in a college course, they must be acquired elsewhere.

One of the secretaries of President Roosevelt's Cabinet began his career as a stenographer. $\mathrm{He}$ is now the Postmaster General. Mr. Andrew Carnegie began his career as a telegraph operator and railroad clerk, and the way was open for his attaining to the position of the greatest steel magnate of America. The problem is to find an opening; and no matter how excellent the natural abilities may be, it is difficult for one to get the opportunity to exercise those abilities unless by beginning in a business to do some specific thing, as I have mentioned.

Following this necessarily imperfect formulation of the kind of training required for the man of affairs, consideration may now be given to the question of its place as to time in an educational scheme. Obviously, it should either follow the course in the secondary school or should be made part of a college course. It requires mature faculties to assimilate the subjects involved. To an increasing extent the establishment of special technical schools and the incorporation into the curricula of universities of business courses are arguments for this position. Holding, as I do, a profound respect for many of the methods which have heretofore been followed in the university courses, I would argue for a combination of a business course with the usual college curriculum. The following general plan, it is believed, will best meet modern conditions :

Let the curriculum for the first two or three years be the same as in the course in arts, and leading to the bachelor's degree; then follow with an elective course of two years or more if necessary, giving a training for the profession or vocation in view.

If the choice is a business career, the two years of elective 
studies should include such subjects as the mathematics, the natural sciences, political economy, commercial law and commercial geography, the modern languages, and, incidentally, such practical subjects as bookkeeping, stenography, etc. Such a combined course as this would in no wise detract from the dignity of the course of arts, but would supplement that course and give the graduate an equipment qualifying him for a business career.

The original university curriculum was calculated as a training for the ministry; and from the beginning a training for the law, medicine and engineering has required a supplemental course. It would only be logical that a training for a business career should be afforded in the same manner, and should be built on the solid foundation of the broad culture which is afforded by the course in arts. I am loath to abate one iota of the advantages and prestige of the usual college course. Let us concede all the advantages of the broad culture which that course implies, but let us add to it the special training which makes for success in practical affairs and for useful citizenship.

There has been a great change of opinion and custom as to college education for business. The development of the material resources of the country, the institution of various departments of effort and enterprise which were unknown when our colleges were planned, have brought about this change. Not only is the business career more attractive, but it is more necessary. The brief survey of occupations which I gave at the outset, as included in the realm of business, sufficiently indicates this fact. We must remember that when our colleges were first planned our urban population was small. Business was then largely confined to retail operations. The country store, where the farmer exchanged his eggs for molasses or calico or codfish, was the prevailing type. To-day nearly one-third of our population is in cities each of over 25,000 inhabitants.

Mercantile business has been expanded, and wholesale operations of vast proportions are the rule. Manufactures, which were unknown in America, now are prevailing interests throughout the country. The United States has become a manufacturing nation. Our exports of manufactured articles in recent years have passed the mark of value of $\$ 1,500,000$ per working day. Commerce, finance, insurance, shipping, transportation - all these present in- 
viting fields for young men of ability and training. Recognition of this fact is found in some of the college statistics. In the first half of the nineteenth century the percentage of Yale graduates in business, as distinguished from the four professions of theology, law, medicine and teaching, was in 4-9. In the second half of the century the percentage had risen to $236-9$.

The general outcome of the movement may be summed up as follows: The law during the nineteenth century approximately enlisted one-third of each college generation. At the beginning of the century the ministry followed closely in second place. Roughly speaking, the law and the ministry were then chosen by two-thirds of the class. Nowadays the law still holds its own, but the ministry has fallen off greatly in relative importance; its place has been taken by the merchant's vocation, which now attracts about onethird of the graduates.

It would not be safe to conclude from this that the kind of men who formerly became clergymen now go into business, though this may be true to some extent. In any case, it is clear that the leadership which naturally falls to the college graduate in this country was formerly chiefly exerted from the bar and the pulpit; that nowadays, however, the industrial leaders are also largely recruited from among college graduates; that the typical college graduate of to-day is no longer the scholar, but the man of affairs.

Such a scheme as I have outlined presupposes less attention in the college course to the dead languages, to metaphysics and ancient history, and thus the saving of time for the special studies required for business pursuits. I believe this to be entirely practicable. I believe one-half of the time spent, usually, in the study of Greek and Latin would be ample. I would not abolish the study of the classics, but would curtail such study unless in preparation for an educational career. To a large extent such study could be pursued in the secondary schools preparatory to the college course. With such a rearrangement a four or five years' course, in which the last two years should be devoted to special study bearing on commercial and industrial pursuits, would be a saving of time and more effective in the equipment of the American citizen for the duties and opportunities confronting him to-day. 